\title{
Changes in exposure to 'life stressors' in the Aboriginal and Torres Strait Islander population, 2002 to 2008
}

\author{
Matthew Stevens ${ }^{1 *}$ and Yin Paradies ${ }^{2}$
}

\begin{abstract}
Background: The Negative Life Events Scale (NLES) has been included in nationally representative surveys of the Indigenous and Australian population since 2002 as a measure of exposure to a range of 'life stressors'. There has been limited reporting or analysis of estimates of the NLES from these surveys. This paper reports changes in exposure to stressors from 2002 to 2008 for the Indigenous population, and examines inter-relationships between eleven NLES items. Data for the 2006 Australian population is also included for comparative purposes.

Methods: Data from the 2002 and 2008 National Aboriginal and Torres Strait Islander Social Surveys (NATSISS) and the 2006 General Social Survey (GSS) were accessed from the Australia Bureau of Statistics in order to determine significant changes in exposure to stressors for the 2002 and 2008 Indigenous population by remoteness and to compare this with the 2006 Australian population. Factor analysis was used to assess the inter-relationships between stressors for the Indigenous and Australian population by remoteness.

Results: In remote locations, between 2002 and 2008, exposure to life stressors decreased significantly for the Indigenous population across seven of the eleven stressors. In non-remote locations, exposure to four of the stressors increased significantly. Exposure to stressors in the 2002 and 2008 non-remote Indigenous population were significantly higher than those for the 2006 Australian population for all items, except 'alcohol and/or drug problems' and 'trouble with the police', which showed no evidence of a difference. The factor analysis of the NLES for the 2002 and 2008 remote and non-remote Indigenous populations and the 2006 Australian population showed a consistent clustering of items into three groups: social transgressions; grief and trauma; and labour market stressors.

Conclusions: The reduction in exposure to life stressors for the remote Indigenous population may be related to policy and practice changes (e.g. more police, income quarantining, housing construction). The differential change in exposure to life stressors between remote and non-remote locations highlights the importance of presenting data for these geographic locations separately.
\end{abstract}

Keywords: Indigenous, Remoteness, Stress, Social and emotional wellbeing, Mental health

\section{Background}

Social and emotional wellbeing (SEWB) is recognised as an important dimension of health across all life stages [1-5]. Recent reports have highlighted the need to collect appropriate measures of SEWB for the Aboriginal and Torres Strait Islander population, who by current indicators experience significantly poorer SEWB than non-Indigenous

\footnotetext{
* Correspondence: matthew.stevens@menzies.edu.au

'Menzies School of Health Research, Institute of Advanced Studies, Charles

Darwin University, PO Box 41096, Casuarina, NT 0811, Australia

Full list of author information is available at the end of the article
}

Australians [3,4,6-8]. The Australian government has responded to these poor outcomes by developing a National Strategic Framework for Aboriginal and Torres Strait Islander Peoples' Mental Health and Social and Emotional Wellbeing [4]. The strategic framework acknowledges SEWB as distinct from mental health, though the two concepts intersect. Specific issues that affect Indigenous peoples' SEWB include grief, loss, trauma, abuse, violence, racism, substance misuse, family breakdown, cultural dislocation and social disadvantage [7-9]. It also notes that solutions aimed at improving SEWB and

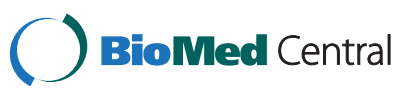


mental health for the Aboriginal and Torres Strait Islander population need to be multidimensional in nature and actively engage the community to build on existing strengths. The efforts to improve SEWB have again been emphasised in the recently released National Aboriginal and Torres Strait Islander Health Plan, 2013-2023 [10]. A speech in 2009 by the Australian Prime Minister suggests a strong commitment from the Australian government at the highest level in 'closing the gap' between Indigenous and non-Indigenous Australians over the next 20 years [11]. This commitment is also supported by the National Partnership Agreement on Closing the Gap in Indigenous Health Outcomes [12]. However, recent reports indicate that, despite efforts to address Indigenous disadvantage over many years, progress against key indicators has been frustratingly slow, although improvement in some socioeconomic measures is evident [13-17].

However, there has been considerable debate centred on how to measure SEWB for Indigenous Australians $[7,18,19]$ with few validated instruments focused on this topic currently available [20]. Additionally, it has been often stated that Indigenous models of health incorporate more holistic notions than Western concepts of health, although some have noted that such holistic notions within Indigenous models of health may have been derived, in part, from Western concepts [21], and that a person's SEWB and other factors such as connection to traditional lands also play an important role for Indigenous people [7,22-24]. Zubrick et al. [25] define SEWB as the emotional and psychological aspects of child and adult development as well as the importance and nature of social and community relationships supporting good health.' SEWB may vary over a person's life course and can mean different things to different people, and can be characterised by being in a stable state, free from illness, feeling good and healthy. Measures of SEWB can measure strengths, weaknesses or a combination of the two [18,25-27].

The Aboriginal Birth Cohort $(\mathrm{ABC})$ study in the Northern Territory (NT) developed a 25 item measure of SEWB called the 'Strong Souls' [26]. A factor analysis of this measure produced a four-factor model that identified the constructs of anxiety, resilience, depression and suicide risk. in this study, the construct of anxiety was found to be associated with feelings of sadness and low mood and not depression, while the expression of anger was verified as a unique symptom of depression for Indigenous people. The Footprints in Time longitudinal study of Indigenous children used subsets of the Strong Souls scale, and found child social and emotional wellbeing was related to life stressors and to parent social and emotional wellbeing, and that lower levels of exposure to stressors were associated with improved reading and learning outcomes in children [28]. The
Western Australian Aboriginal Child Health Survey used the Strengths and Difficulties Questionnaire (SDQ) measure [29], which was found to be a reasonable measure of mental health and well-being in Aboriginal Australian children and young people [27]. Findings from this survey indicated that younger (4-11 years), males, and less geographically isolated Indigenous children were at more risk of being having clinically significant emotional or behavioural difficulties, and that Indigenous children were at a higher risk than non-Indigenous children [25].

Another way of measuring SEWB is through proxy indicators such as exposure to stressful events. The above discussed measures of SEWB have predominantly been used in samples of children and young adults. A more general measure that can be applied to adults in different population groups was required. In 2002, the Australian Bureau of Statistics (ABS) introduced a new measure of SEWB into its social and health surveys; the Negative Life Events Scale (NLES) [30,31]. The NLES was developed in consultation with peak Indigenous bodies across Australia with the aim of providing a comparable measure of SEWB for both Indigenous and nonIndigenous Australians [30]. Currently the NLES is being used in both Indigenous and general population social and health surveys carried out by the ABS. A modified version of the NLES has been used in a study of housing and Aboriginal child health, which found it generally performed well in the diverse Indigenous population sampled [18]. However, there has been scant published research on the NLES using data from ABS surveys $[7,32,33]$, and $A B S$ has not released an information paper on how the measure was tested for reliability. In response to this dearth of information this paper will use data from the 2002 and 2008 National Aboriginal and Torres Strait Islander Social Survey, and the 2006 General Social Survey to:

1. Determine and compare the factor structure for the NLES for the 2002 and 2008 Aboriginal and Torres Strait Islander population by remoteness, and for the 2006 total Australian non-remote population.

2. Assess changes in exposure to life stressors in the Aboriginal and Torres Strait Islander population from 2002 to 2008 by remoteness, and compare these to the non-remote 2006 Australian population.

\section{Methods}

\section{Surveys and sampling design}

The National Aboriginal and Torres Strait Islander Social Surveys (NATSISS) were carried out in 2002 and 2008, and collected information on geographic, demographic, social, economic, cultural, health and behavioural domains. Full details of sample design, collection methods, and data quality for these surveys have been reported elsewhere 
$[30,34]$. In brief, the sampling frame included all Indigenous people who were usual residents in private dwellings (flats, houses, units and other structures used as private residents). The NATSISS covered remote and non-remote areas of Australia, including discrete Indigenous communities from the Northern Territory, Queensland, South Australia and Western Australia. The ABS defines remote and non-remote regions in accordance with the Australian Standard Geographic Classification, which classifies the remoteness of a locality according to its distance to other localities of varying population sizes [35]. In this remoteness model, the population size of a locality is used as a proxy for the number and types of services available; so the further the location is from more populous areas determines its remoteness. The community sample was obtained by taking a random selection of discrete Indigenous communities selected from a specially developed Indigenous Community Frame that was constructed using information obtained from the 2001 and 2006 Census of Population and Housing, and 2001 and 2006 Community Housing and Infrastructure Needs Survey [34,36]. Within selected communities, dwellings were randomly selected and within each household a random sub-sample of usual residents was selected for inclusion in the survey. Dwellings in noncommunity areas were selected using a stratified multistage area sample, with the likelihood of a collection district being selected being based on the number of dwellings containing Indigenous persons in that collection district ascertained from the previous census. All interviews were face-to-face and carried out by trained interviewers. The scope and sample size for each survey used in this paper are detailed in Table 1 . To ensure comparability across surveys, all analyses were restricted to respondents aged 18 years and over.

The 2006 General Social Survey (GSS) is the general population survey equivalent of the NATSISS. The sampling frame included all people aged 18 years and over who were usual residents in private dwellings, living in both urban and rural areas in all states and territories, except for very remote parts of Australia (approximately $2 \%$ of the population). Dwellings in the survey were selected at random using multi-stage area sampling techniques, and within the selected dwelling, a random sub-sample of one person aged 18 years or over was enumerated. All interviews were face-to-face and carried out by trained interviewers. The survey is designed to produce reliable estimates at the national level and for each state and territory (though estimates for the NT will be skewed, as $20 \%$ of the population (mostly Aboriginal) live in very remote areas). As the GSS is a general population survey it includes Aboriginal and Torres Strait Islander people in the sample. However, there is no identifier in the survey and as such, this population group could not be excluded from the analysis. However, the Aboriginal and Torres Strait Islander population make up make up only $2 \%$ of the total population in non-remote areas and so will bias only very minimally towards the null in the comparisons between the NATSISS and GSS. The final sample size for the 2006 GSS is shown in Table 1. For the purposes of this paper the population in the GSS will be referred to as the 2006 Australian population.

\section{The negative life events scale}

We derived estimates for eleven items of the NLES in 2002 and 2008 by remoteness for the Indigenous population, and for the Australian population in 2006 (for comparability and to contextualise Indigenous estimates). This paper will not consider the five items ('mental illness', 'member of family sent to jail/currently in jail', 'overcrowding at home', 'pressure to fulfil cultural responsibilities' and 'discrimination/racism') as they were not collected across both remote and non-remote Indigenous surveys, and so could not be compared between the Indigenous and general population surveys. The eleven NLES items that are comparable between these three surveys are: gambling problem; alcohol and/or drug related problem; witness to violence; abuse or violent crime; trouble with the police; divorce or separation; not able to get a job; lost job, redundant, sacked; death-family/close friend; serious illness or disability; and serious accident. In the 2002 NATSISS and the 2006 GSS, the NLES asks respondents, 'have any of these things (list of stressors or negative life events) been a problem for you or your family or friends during the last year?' Respondents could answer yes or no. In the 2008 NATSISS, this information was collected separately for the respondent and for their family and close friends. A variable was derived that included both pieces of information to ensure comparability between the 2002, 2006 and 2008 surveys.

Table 1 Data sources, sample size and scope for analyses

\begin{tabular}{llll}
\hline Name of survey & Year & Sample size $(\mathbf{n})^{\mathbf{1}}$ & Geographic scope for analysis $^{\text {National Aboriginal and Torres Strait Islander Social Survey }{ }^{2}}$ \\
General Social Survey (GSS) & 2002 & 8,523 & Non-remote \& remote \\
National Aboriginal and Torres Strait Islander Social Survey ${ }^{2}$ & 2006 & 13,375 & Non-remote \\
\hline
\end{tabular}

(1) 18 years and over, (2) NATSISS. 
Inter-relationship between NLES items (dimensionality)

Factor analyses (principle component factor method) were conducted on the 2006 GSS and separately for remote and non-remote samples of the 2002 and 2008 NATSISS. The factor analysis (FA) was performed to assess patterns of association between items and to identify the factor structure of the NLES. The stratification by remoteness was necessary to account for the varying social, economic and cultural circumstances of Indigenous Australians in remote vs. non-remote areas, and to allow for a comparison with the 2006 total population. Specifically, Indigenous people living in remote areas have a much higher proportion of Indigenous language speakers; have poorer socioeconomic circumstances, and suffer from poorer physical health [8]. The decision on the number of factors to retain included a combination of interpretability, observing scree plots and retaining factors with Eigenvalues greater than one [37]. An orthogonal rotation was applied to the retained factors to facilitate interpretation and comparison between surveys by remoteness [38]. A tetrachoric correlation matrix would have been preferred to a standard Pearson's correlation matrix for use in the factor analyses (as responses were binary and therefore only approximately linear at best). However, the former was not possible due to the weighting system used by the $\mathrm{ABS}$ and limitations of the statistical package (Stata v8.2@) made available by the ABS via the Remote Access Data Laboratory $[30,39,40]$. In practice, however, findings using a standard correlation matrix tend to be largely comparable to a tetrachoric matrix [26]. All analyses were carried out using weighted data that was benchmarked to the estimated residential population at the time of the survey.

\section{Changes in NLES items}

Statistically significant differences between 2002 and 2008 in exposure to life stressors in the previous 12 months were determined using the standard formula for the difference between survey proportions (see below), which includes information on the standard error and therefore takes into account the standard deviation, the sample size (n) and the weighted data $(\mathrm{N})$.

$$
T=\left[\frac{a b s(x-y)}{S E(x-y)}\right]
$$

where

$$
S E(x-y)=\sqrt{[S E(x)]^{2}+[S E(y)]^{2}}
$$

and $\mathrm{T}=$ the test statistic

$S E(x-y)=$ standard error of the difference in two proportions

$a b s(\mathrm{x}-\mathrm{y})=$ the absolute difference between the two proportions being compared
$S E(x)$ and $S E(y)=$ the standard error of each of the two proportions being compared

The T-statistic in this formula is then compared to Student's T-distribution to determine significance. The change in the total number of stressors' is shown for the 2002 and 2008 surveys by remoteness and for the 2006 Australian population. NLES estimates for the 2002 NATSISS were sourced from survey data cubes [41], while estimates for the 2008 NATSISS and 2006 GSS were derived from the Confidentialised Unit Record File (CURF) accessed remotely using the ABS Remote Access Data Laboratory (RADL) [34,39,40]. Ethics approval for this research was obtained through the Human Research Ethics Committee of the Northern Territory Department of Health and Menzies School of Health Research (reference number: 05/03).

\section{Results}

Factor structure of the NLES

A 3-factor solution of the NLES items was optimal for both the 2002 and 2008 remote and non-remote Aboriginal and Torres Strait Islander population (Tables 2 and 3). The loadings in these tables represent the correlation between the NLES item and the factor score (which represents the construct being measured). The loadings in bold show which factor the item most heavily loaded on (and above 0.3) and facilitate interpretation [38]. The 2002 remote and non-remote solutions explained $53 \%$ and $45 \%$ of the variation in the eleven stressors respectively (Table 2). In the 2002 remote FA, the factor labelled social transgressions and labour market stressors includes witness to violence, abuse or violent crime, alcohol or drug related problems, trouble with the police, gambling problem and not able to get a job. This factor was also present in the non-remote FA, though the item pertaining to unemployment only had a loading of 0.25 and loaded higher on the factor specifically related to labour market stressors (not being able to get a job and there being no jobs to get), which was also present for the remote FA. The third factor in both the remote and non-remote FA predominantly pertained to stressors associated with grief and trauma, and included living with someone with a serious illness or disability, knowing someone in a serious accident, and the death of a family member or close friend. The divorce or separation item was mostly evenly loaded across all three factors in the remote FA, while for the non-remote FA, it loaded highest on the labour market stressors factor.

Table 3 presents the FA by remoteness for the 2008 Indigenous population. The non-remote and remote solutions both explained $47 \%$ of the variation between NLES items. The 2008 remote and non-remote factor structures were very similar to those observed in 2002, with broadly the same three constructs identified. In 2008 for both remote and non-remote FAs, the construct 
Table 2 Rotated factor analyses of NLES items for 2002 Indigenous population by remoteness

\begin{tabular}{|c|c|c|c|c|c|c|}
\hline \multirow[b]{2}{*}{ NLES item } & \multicolumn{3}{|c|}{ Remote loadings } & \multicolumn{3}{|c|}{ Non-remote loadings } \\
\hline & $\begin{array}{l}\text { Social transgressions \& } \\
\text { labour market stressors }\end{array}$ & $\begin{array}{c}\text { Grief and } \\
\text { trauma }\end{array}$ & $\begin{array}{l}\text { Labour market } \\
\text { stressors }\end{array}$ & $\begin{array}{c}\text { Social } \\
\text { transgressions }\end{array}$ & $\begin{array}{c}\text { Labour market } \\
\text { stressors \& } \\
\text { relationship } \\
\text { breakdown }\end{array}$ & $\begin{array}{c}\text { Grief and } \\
\text { trauma }\end{array}$ \\
\hline Witness to violence & 0.79 & 0.11 & 0.06 & 0.68 & 0.06 & 0.19 \\
\hline Abuse or violent crime & 0.75 & 0.00 & 0.17 & 0.68 & -0.01 & 0.13 \\
\hline Alcohol and/or drug problem & 0.74 & 0.24 & 0.03 & 0.70 & 0.17 & 0.08 \\
\hline Police trouble & 0.65 & 0.13 & 0.13 & 0.68 & 0.10 & 0.04 \\
\hline Gambling problem & 0.65 & 0.25 & 0.12 & 0.52 & 0.27 & -0.04 \\
\hline Not able to get a job & 0.42 & 0.05 & 0.52 & 0.16 & 0.66 & 0.11 \\
\hline Lost job, made redundant, sacked & 0.06 & 0.05 & 0.91 & 0.04 & 0.76 & 0.04 \\
\hline Divorce or separation & 0.32 & 0.30 & 0.25 & 0.24 & 0.42 & 0.05 \\
\hline Serious illness or disability family & 0.09 & 0.70 & 0.05 & 0.10 & 0.21 & 0.63 \\
\hline Serious accident someone close & 0.17 & 0.71 & 0.01 & 0.19 & -0.08 & 0.61 \\
\hline Death family member/close friend & 0.19 & 0.59 & 0.16 & 0.06 & 0.08 & 0.65 \\
\hline Eigen value & 2.95 & 1.58 & 1.25 & 2.28 & 1.36 & 1.28 \\
\hline Variation explained (\%) & $27 \%$ & $14 \%$ & $11 \%$ & $21 \%$ & $12 \%$ & $12 \%$ \\
\hline Cumulative variation (\%) & $27 \%$ & $41 \%$ & $53 \%$ & $21 \%$ & $33 \%$ & $45 \%$ \\
\hline
\end{tabular}

Note: Item loadings in bold indicate the factor they most heavily loaded on (and above 0.3).

identifying social transgressions did not include the item relating to unemployment, but included all the other items identified in the 2002 FA. The labour market stressors construct came out separately in both the remote and non-remote FA's. The grief, trauma and relationship breakdown construct was consistent between remote and non-remote FA's in 2008, and differed to those seen in 2002 with the inclusion of the divorce or separation stressor.

Table 4 shows the 3-factor solution for the 2006 non-remote total population, which explained $42 \%$ of the variation in the NLEs items. The three constructs

Table 3 Rotated factor analyses of NLES items for 2008 Indigenous population by remoteness

\begin{tabular}{|c|c|c|c|c|c|c|}
\hline \multirow[b]{2}{*}{ NLES item } & \multicolumn{3}{|c|}{ Remote loadings } & \multicolumn{3}{|c|}{ Non-remote loadings } \\
\hline & $\begin{array}{c}\text { Social } \\
\text { transgressions }\end{array}$ & $\begin{array}{c}\text { Grief, trauma \& } \\
\text { relationship } \\
\text { breakdown }\end{array}$ & $\begin{array}{c}\text { Labour market } \\
\text { stressors }\end{array}$ & $\begin{array}{c}\text { Social } \\
\text { transgressions }\end{array}$ & $\begin{array}{c}\text { Grief, trauma \& } \\
\text { relationship } \\
\text { breakdown }\end{array}$ & $\begin{array}{c}\text { Labour market } \\
\text { stressors }\end{array}$ \\
\hline Witness to violence & 0.68 & 0.11 & 0.05 & 0.72 & 0.14 & 0.05 \\
\hline Abuse or violent crime & 0.70 & 0.11 & -0.08 & 0.75 & 0.11 & -0.04 \\
\hline Alcohol and/or drug problem & 0.73 & 0.17 & 0.19 & 0.66 & 0.06 & 0.32 \\
\hline Police trouble & 0.64 & 0.12 & 0.13 & 0.68 & 0.01 & 0.20 \\
\hline Gambling problem & 0.65 & -0.02 & 0.27 & 0.56 & 0.00 & 0.35 \\
\hline Not able to get a job & 0.25 & 0.06 & 0.66 & 0.24 & 0.06 & 0.66 \\
\hline Lost job, made redundant, sacked & 0.05 & 0.05 & 0.81 & 0.11 & 0.11 & 0.67 \\
\hline Divorce or separation & 0.14 & 0.37 & 0.05 & 0.30 & 0.46 & -0.27 \\
\hline Serious illness or disability family & 0.08 & 0.59 & 0.27 & -0.02 & 0.61 & 0.29 \\
\hline Serious accident someone close & 0.12 & 0.61 & 0.03 & 0.07 & 0.56 & 0.20 \\
\hline Death family member/close friend & 0.17 & 0.68 & -0.02 & 0.15 & 0.65 & -0.03 \\
\hline Eigen value & 2.44 & 1.39 & 1.31 & 2.47 & 1.38 & 1.36 \\
\hline Variation explained (\%) & $22 \%$ & $13 \%$ & $12 \%$ & $22 \%$ & $13 \%$ & $12 \%$ \\
\hline Cumulative variation (\%) & $22 \%$ & $35 \%$ & $47 \%$ & $22 \%$ & $35 \%$ & $47 \%$ \\
\hline
\end{tabular}

Note: Item loadings in bold indicate the factor they most heavily loaded on (and above 0.3). 
Table 4 Rotated factor analysis of NLES items for 2006 non-remote total population

\begin{tabular}{|c|c|c|c|}
\hline \multirow[b]{2}{*}{ NLES item } & \multicolumn{3}{|c|}{ Non-remote loadings } \\
\hline & $\begin{array}{c}\text { Social } \\
\text { transgressions }\end{array}$ & $\begin{array}{l}\text { Labour market } \\
\text { stressors }\end{array}$ & $\begin{array}{c}\text { Grief and } \\
\text { trauma } \\
\end{array}$ \\
\hline Witness to violence & 0.67 & 0.07 & 0.14 \\
\hline Abuse or violent crime & 0.71 & -0.06 & 0.10 \\
\hline $\begin{array}{l}\text { Alcohol and/or drug } \\
\text { problem }\end{array}$ & 0.60 & 0.30 & 0.00 \\
\hline Police trouble & 0.64 & 0.11 & -0.06 \\
\hline Gambling problem & 0.44 & 0.26 & -0.15 \\
\hline Not able to get a job & 0.12 & 0.74 & 0.04 \\
\hline $\begin{array}{l}\text { Lost job, made } \\
\text { redundant, sacked }\end{array}$ & 0.03 & 0.77 & 0.07 \\
\hline Divorce or separation & 0.28 & 0.27 & 0.16 \\
\hline $\begin{array}{l}\text { Serious illness or } \\
\text { disability family }\end{array}$ & 0.02 & 0.13 & 0.60 \\
\hline $\begin{array}{l}\text { Serious accident } \\
\text { someone close }\end{array}$ & 0.18 & 0.02 & 0.49 \\
\hline $\begin{array}{l}\text { Death family member/ } \\
\text { close friend }\end{array}$ & 0.03 & 0.04 & 0.68 \\
\hline Eigen value & 2.05 & 1.41 & 1.15 \\
\hline Variation explained (\%) & $18.7 \%$ & $12.8 \%$ & $10.5 \%$ \\
\hline Cumulative variation (\%) & $18.7 \%$ & $31.5 \%$ & $42.0 \%$ \\
\hline
\end{tabular}

Note: Item loadings in bold indicate the factor they most heavily loaded on (and above 0.3).

as identified by the 3 -factor solution were most similar to those obtained for the 2002 Indigenous FA's, and included social transgressions, grief and trauma, and labour market stressors. Similar to the 2002 remote FA, the item for divorce and separation loaded across all three factors.

\section{Changes in exposure to stressors}

Figure 1 presents the percentage of people reporting exposure to the eleven stressors in the last 12 months for the Aboriginal and Torres Strait Islander non-remote population (2002 and 2008), and the Australian (nonremote) population (2006). Between 2002 and 2008 there was evidence of a significant decline in exposures in the Aboriginal and Torres Strait Islander population for stressors: 'not able to get a job' $(\mathrm{T}=2.13, \mathrm{p}=0.033)$, 'divorce or separation' $(\mathrm{T}=3.40, \mathrm{p}<0.001)$, and 'death of a family member or close friend' $(\mathrm{T}=2.34, \mathrm{p}=0.019)$; and evidence of significant increases for: 'alcohol or drug related problems' $(\mathrm{T}=2.15, \mathrm{p}=0.031)$ and 'serious illness or disability in the family' $(\mathrm{T}=2.25, \mathrm{p}=0.024)$. Exposure to the eleven stressors' for the Aboriginal and Torres Strait Islander population in 2008 were significantly higher than in the 2006 Australian population, except for 'alcohol or drug related problems' and 'trouble with the police'. Between 2002 (not reported) and 2006, exposure to stressors for the Australian population remained largely unchanged, with no evidence of significant changes [42,43].

Figure 2 shows exposure to stressors for the remote Aboriginal and Torres Strait Islander population in 2002 and 2008. There was evidence of a significant decline in exposure for ten of the eleven stressors from 2002 to 2008, with 'lost job/made redundant' the exception (no significant difference). Exposure to stressors that declined by more than $10 \%$ over the period included: 'witness to violence', 'abuse or violent crime', 'alcohol or drug related problems', 'gambling problem', and 'death family member/close friend' (for all these items $\mathrm{T}>3.76$, $\mathrm{p}<0.001)$.

Exposure to stressors' for both the remote and nonremote Aboriginal and Torres Strait Islander population

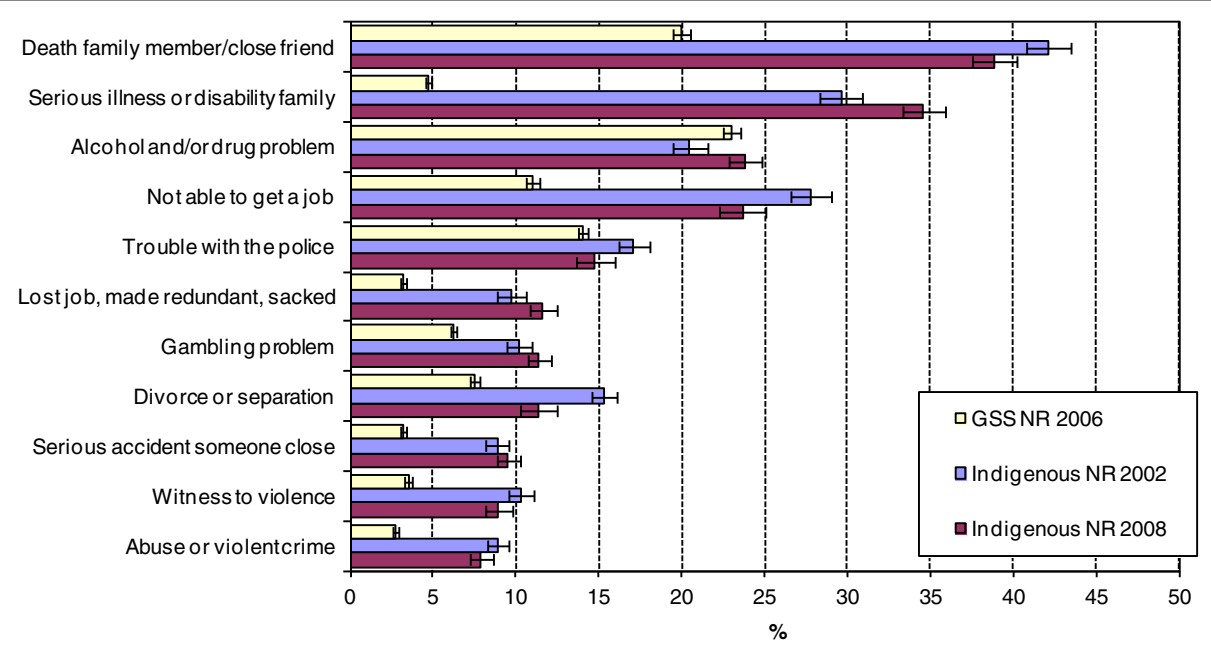

Figure 1 Estimates (standard errors) of NLES items for the 2002 and 2008 non-remote Indigenous population and the 2006 non-remote general population. Source: 2002 and 2008 NATSISS, and 2006 GSS data cubes and CURF generated accessed via RADL. NOTE: NR= Non-remote. 


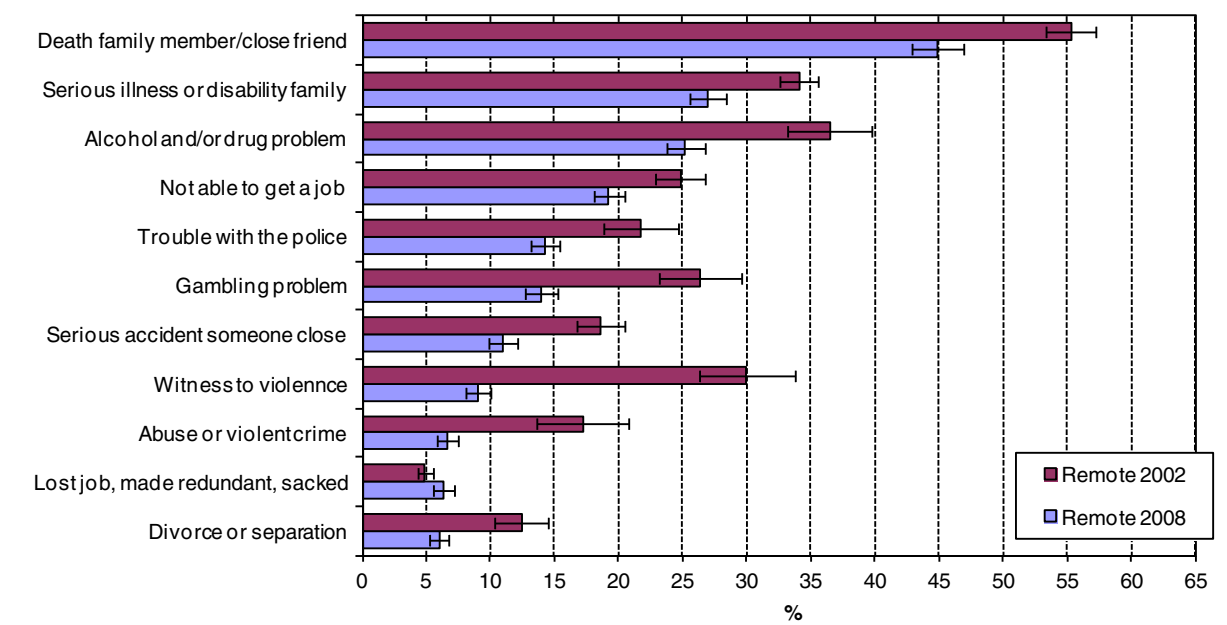

Figure 2 Estimates (standard errors) of NLES items for remote Indigenous population, 2002 to 2008. Source: 2002 and 2008 NATSISS CURF accessed via RADL.

showed a distinct pattern of convergence from 2002 to 2008. In 2002, exposure to seven of the eleven stressors for the remote Aboriginal and Torres Strait Islander population showed evidence of being significantly higher than the non-remote population. They were: 'witness to violence' $(\mathrm{T}=5.58, \mathrm{p}<0.001)$, 'abuse or violent crime' $(\mathrm{T}=2.49$, $\mathrm{p}=0.013)$, 'alcohol or drug related problems' $(\mathrm{T}=4.80$, $\mathrm{p}<0.001)$, 'gambling problem' $(\mathrm{T}=4.99, \mathrm{p}<0.001)$, 'lost job, made redundant, sacked' $(\mathrm{T}=5.20, \mathrm{p}<0.001)$, 'serious illness or disability family' ( $\mathrm{T}=2.26, \mathrm{p}=0.024)$, 'serious accident someone close' $(\mathrm{T}=5.33, \mathrm{p}<0.001)$, and 'death family member/close friend' $(T=5.32, p<0.001)$. In contrast, exposure to stressors in 2008 for the remote Aboriginal and Torres Strait Islander population showed evidence of being significantly higher than the non-remote population for only one item, 'death family member/close friend' ( $\mathrm{T}=2.47, \mathrm{p}=0.014)$, and lower for four items: 'not able to get a job' $(\mathrm{T}=2.59, \mathrm{p}<0.01)$, 'lost job, made redundant, sacked' ( $\mathrm{T}=4.40, \mathrm{p}<0.001)$, 'divorce or separation' $(\mathrm{T}=5.08, \mathrm{p}<0.001)$, and 'serious illness or disability in family' $(\mathrm{T}=4.03, \mathrm{p}<0.001)$.

Figures 3 and 4 show the change from 2002 to 2008 in the number of stressors reported for the non-remote and remote Aboriginal and Torres Strait Islander population respectively. A clear pattern emerges with no significant change between 2002 and 2008 in the number of reported stressors for the non-remote population $(\mathrm{T}<1.78, \mathrm{p}>0.075)$. However, in the remote population

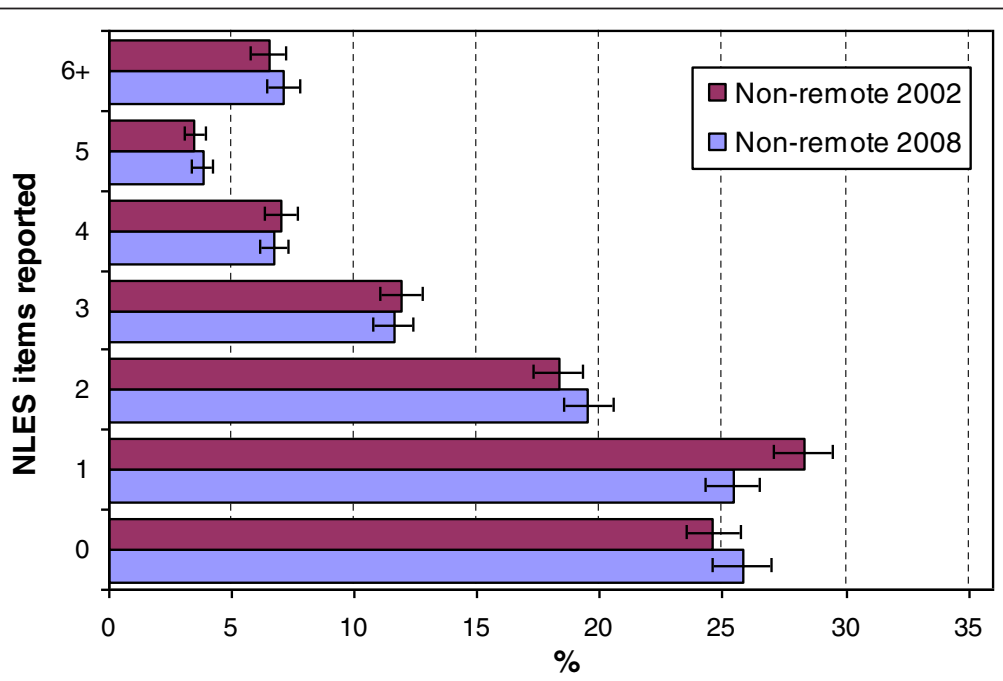

Figure 3 Change in the number of NLES items reported for the non-remote Indigenous population, 2002 to 2008. 


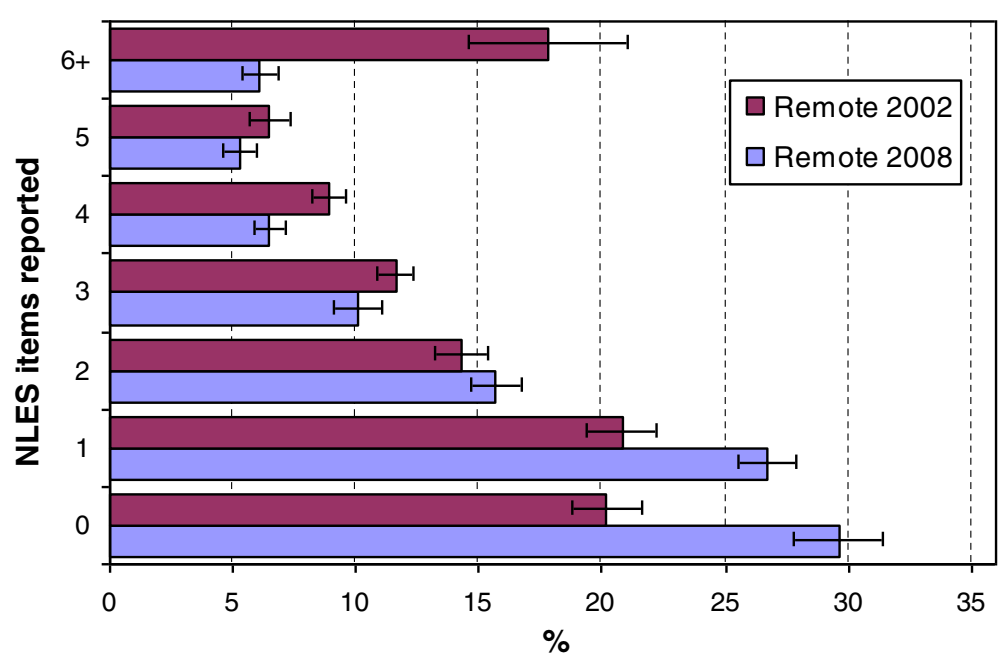

Figure 4 Change in the number of NLES items reported for the remote Indigenous population, 2002 to 2008.

there was a significant increase in the percentage of the Aboriginal and Torres Strait Islander population reporting exposure to only one $(\mathrm{T}=3.2, \mathrm{p}<0.01)$ or no stressors $(\mathrm{T}=4.12, \mathrm{p}<0.01)$, and a significant decrease in the percentage reporting six or more stressors $(\mathrm{T}=3.57, \mathrm{p}<0.01)$.

\section{Discussion}

\section{Patterns of association between NLES items}

The factor analysis of eleven stressors for the 2002 and 2008 Aboriginal and Torres Strait Islander population identified three domains, social transgressions, labour market stressors, and grief and trauma in both the remote and non-remote population. The only stressor not to have a loading above 0.5 on at least one of the factors was the item 'divorce or separation', which would indicate that this stressor is not a good discriminator in the scale and is consistent with a psychometric assessment of this scale used in remote Indigenous communities [18]. These three domains were also observed in factor analyses of the 2004/5 non-remote Indigenous population, the 2002 and 2006 Australian population [44], and in the Northern Territory (Australia) Indigenous population [32]. Although there was consistency in the pattern observed in the factor structure between remote and non-remote Aboriginal and Torres Strait Islander populations and the Australian population, the exposure to stressors in the past 12 months were nearly always lower in the Australian population compared with the Aboriginal and Torres Strait Islander population [44]. So, while absolute levels of reporting of stressors were significantly higher for the Aboriginal and Torres Strait Islander population, patterns of association between the stressors were consistent. This finding shows that the NLES, as a measure of SEWB, has good construct validity for the Aboriginal and Torres Strait Islander and
Australian population when used in population surveys (see also $[18,41]$ ).

The grouping of items on the social transgression factor indicates that these types of problems co-occur within the community context and is consistent with other research highlighting the inter-connectivity between different aspects of community dysfunction [9,45-49]. For example, Phillips [9] conducted research on alcohol, marijuana and gambling in a remote North Queensland Indigenous community and found people gambled to win money to buy food for the household, and it was seen as a way to alleviate poverty, particularly in households where the husband spent a large proportion of his income on alcohol and marijuana. The inter-relatedness of the stressors on the social transgressions factor indicates that initiatives addressing the negative consequences of community violence and unemployment among other elements of the social transgression factor may go some way to alleviating problems related to gambling or alcohol and drug problems.

\section{Exposure to stressors}

There was evidence of differential trends in exposure to stressors for the Aboriginal and Torres Strait Islander population by remoteness between 2002 and 2008. In the remote population there was evidence of a decrease in exposure to ten of the eleven stressors from 2002 to 2008, while for the non-remote population there was a mixture of increases and declines in exposure to stressors. In the non-remote population, there was an increase in exposure to 'alcohol and/or drug problem', and 'knowing someone with a serious illness or disability'. Alcohol, drug and gambling problems, as well as unemployment, have been shown to be associated with poor physical and mental ill-health in the Indigenous 
population [50,51], while an increased burden of care may be associated with knowing others who have a serious illness or disability. A 2007 report into gambling in the Aboriginal and Torres Strait Islander population of New South Wales found gambling to be the cause of significant problems including parents not looking after children, increased family and community tensions and more contact with the criminal justice system [52]. This research, like much before it and in related areas of alcohol and substance misuse have identified the need to provide culturally relevant services for Aboriginal and Torres Strait Islander people, and the need to bring the problem out into the open, to reduce aspects of shame and stigma in people who are affected by alcohol, drug or gambling problems [53-56].

The declines in exposure to stressors observed in the remote Aboriginal and Torres Strait Islander population and the small increases observed for some items in the non-remote Indigenous population are in contrast to trends in the general population, which remained steady over the 2002 to 2006 period [42-44]. Exposure to stressors was higher in the non-remote Aboriginal and Torres Strait Islander population (2002 and 2008) compared with the 2006 Australian population, except for 'alcohol and/or drug problems' and 'trouble with the police', which showed no evidence of a difference. However, the differences observed in the 'alcohol and/or drug problems' should be treated with some caution given evidence that both the 2002 and 2008 NATSISS substantially underestimate levels of high risk alcohol use among Indigenous people due, in part, to the highly sensitive nature of the topic for Indigenous people and the lack of privacy in reporting this information in the NATSISS $[57,58]$.

There are a number of possible causes for the decreases observed in exposure to stressors for the remote Aboriginal and Torres Strait Islander population. Just prior to the 2008 NATSISS, the Commonwealth government introduced the 2007 Northern Territory Emergency Response Act (NTER), in response to the Little Children are Sacred report [46], which highlighted high levels of child neglect and sexual abuse in remote Indigenous communities in the NT. The intention of the NTER was to stabilise communities through the banning of alcohol, improve safety through increasing police presence, reduce crowding through significant injection of funding into new housing, and the quarantining of half of all welfare, to ensure money is spent on necessities (e.g. rent, food, and clothing).

In addition to the NTER, the NT government introduced policy aimed at closing the gap between Indigenous and non-Indigenous Territorians over a generation, which included improving community safety in remote Indigenous communities $[59,60]$. The practice and programs consequent to these policy shifts may have influenced responses to NLES items for the remote Australian
Indigenous population, as approximately $40 \%$ of this population are located in the NT. The research on gambling in remote Indigenous communities indicates that frequency and stake size in community card games increases on paydays and diminishes over the following days $[47,49,61,62]$. The less cash available due to welfare quarantining may have reduced the frequency and stake size of bets in community card games leading to a reduction in harm associated with gambling. Reductions in alcohol supplies to communities and increased police presence may also have contributed to the declines observed for 'alcohol and/or drug problems', 'witness to violence' and 'being abused or a victim of violent crime'.

\section{Limitations}

There were some items collected in the NATSISS which could not be compared between the Indigenous and general population surveys. In addition, there was no Indigenous identifier in the GSS and so it was necessary to utilise the Australian population as a proxy for the non-Indigenous population, creating a small bias towards the null. The convergence in exposure to stressors observed for the remote and non-remote Aboriginal and Torres Strait Islander population in 2008 requires more detailed analyses to further unpack the meaning of this finding. For example, exploring the correlates of individual stressors from the NLES would help in identifying other factors that may influence exposure to stressors, particularly those related to social transgressions.

\section{Conclusion}

The need to improve SEWB has recently been highlighted in the National Aboriginal and Torres Strait Islander Health Plan, 2013-2023 [10], with stress recognised as a key element of SEWB for Indigenous peoples [63]. Investigating data sources and instruments that can effectively monitor changes in stressors is therefore important in evaluating efforts to improve Indigenous health. The factor analysis of the NLES showed consistency in use across the different ABS surveys for both the Indigenous (2002 and 2008) and general population (2006). A key strength of the NLES is that it is used widely in ABS surveys and provides a measure of exposure to life stressors, which can be monitored for changes over time. This is particularly significant given the largescale Indigenous policy and program changes that have occurred in recent years, including income quarantining as part of the NTER and the introduction of the Family Responsibilities Commission in North Queensland, both of which have similar objectives (child safety, school attendance, lawful behaviour, responsible tenancy). Both of these policies have been designed to improve social accountability and rebuild safe social norms within these remote Aboriginal and Torres Strait Islander populations. 
The significant decreases observed in exposure to stressors for the remote Aboriginal and Torres Strait Islander population indicate that there are positive changes occurring. Evidence of increases in exposure to some of the stressors reported on in the non-remote Aboriginal and Torres Strait Islander population require more detailed study. These differential changes within the Indigenous population between locations highlight the importance of presenting data for the Indigenous population by remoteness.

\begin{abstract}
Abbreviations
ABS: Australian bureau of statistics; CURF: Confidentialised unit record file; FA: Factor analysis; GSS: General social survey; NATSIHS: National aboriginal and torres strait islander health survey; NATSISS: National aboriginal and torres strait islander social survey; NLES: Negative life events scale; NR: Non-remote; NTER: Northern territory emergency response act; RADL: Remote access data laboratory; SEWB: Social and emotional wellbeing.
\end{abstract}

\section{Competing interests}

The authors declare that they have no competing interests.

\section{Authors' contributions}

MS carried out all statistical analyses and was responsible for the overall drafting of the manuscript. YP drafted aspects of, and provided critical comment on, the manuscript. Both authors read and approved the final manuscript.

\section{Acknowledgements}

The first author wishes to acknowledge Gambling Research Australia for funding the initial research. Both authors would like to thank the Aboriginal and Torres Strait Islander people who participated in the survey and the Australian Bureau of Statistics for collecting and making the data available.

\section{Author details}

${ }^{1}$ Menzies School of Health Research, Institute of Advanced Studies, Charles Darwin University, PO Box 41096, Casuarina, NT 0811, Australia. ${ }^{2}$ Centre for Citizenship and Globalisation, Faculty of Arts and Education, Deakin University, 221 Burwood Hwy, Burwood, VIC 3125, Australia.

Received: 6 June 2013 Accepted: 6 February 2014

Published: 11 February 2014

\section{References}

1. Bowling A, Browne PD: Social networks, health, and emotional well-being among the oldest Old in London. J Gerontol 1991, 46(1):S20-S32.

2. Cadman D, Boyle M, Szatmari P, Offord DR: Chronic illness, disability, and mental and social well-being: findings of the Ontario child health study. Pediatrics 1987, 79(5):805-813.

3. Martin GM: On social and emotional wellbeing and Indigenous Australians. Australian eJournal for the Advancement of Mental Health 2008, 7(3):1-5.

4. Social Health Reference Group: National Strategic Framework for Aboriginal and Torres Strait Islander Peoples' Mental Health and Social and Emotional Well Being (2004-2009). In Edited by Council AHMA. Canberra: Office of Aboriginal and Torres Straight Islander Health; 2004:1-79.

5. Henderson G, Robson C, Cox L, Dukes C, Tsey K, Haswell M: Social and emotional wellbeing of Aboriginal and Torres Strait Islander people within the broader context of the social determinants of health. In Beyond Bandaids: Exploring the Underlying Social Determinants of Aboriginal Health. Darwin: Cooperative Research Centre for Aboriginal Health; 2007:136-164.

6. Carson B, Dunbar T, Chenhall R, Bailie R: Social Determinants of Indigenous Health. 1st edition. Crows Nest, NSW: Allen \& Unwin; 2007.

7. Australian Institute of Health \& Welfare: Measuring the social and emotional wellbeing of Aboriginal and Torres Strait Islander peoples. Canberra: AlHW: 2009.

8. Australian Bureau of Statistics, Australian Institute of Health \& Welfare: The Health and Welfare of Australia's Aboriginal and Torres Strait Islander Peoples, 2013. In Cat no 47040. Canberra: Commonwealth of Australia; 2013.
9. Phillips G: Addictions and Healing in Aboriginal Country. Canberra: Aboriginal Studies Press; 2003.

10. Australian Government: National Aboriginal and Torres Strait Islander Health Plan, 2013-2023. In Edited by Health Do. Canberra: Commonwealth of Australia; 2013.

11. Rudd K: Closing the gap on indigenous disadvantage: the challenge for Australia. In Speeches. Canberra: Commonwealth of Australia; 2009.

12. Australian Government: National partnership agreement on closing the gap in indigenous health outcomes. In Edited by Services DoS. Canberra: Commonwealth of Australia; 2008.

13. Banks $\mathrm{G}$ : Indigenous disadvantage: are we making progress? Adelaids: Committee for Economic Development in Australia; 2005.

14. Steering Committee for the Review of Government Service Provision: Overcoming indigenous disadvantage: key indicators 2007. In Edited by Steering Committee for the Review of Government Service Provision. Canberra: Productivity Commission; 2007.

15. Altman J, Biddle N, Hunter B: The challenge of 'closing the gaps' in Indigenous socioeconomic outcomes. In Australia 2020 Summit. Canberra: Centre for Aboriginal and Economic Research, ANU; 2008.

16. Altman JC, Biddle $\mathrm{N}$, Hunter $\mathrm{BH}$ : A historical perspective on indigenous socioeconomic outcomes in Australia, 1971-2001. Aust Econ Hist Rev 2005, 45(3):273-295.

17. Steering Committee for the Review of Government Service Provision: Overcoming indigenous disadvantage: key indicators 2011. Canberra: Productivity Commission; 2011.

18. Kowal E, Gunthorpe W, Bailie R: Measuring emotional and social wellbeing in aboriginal and Torres strait islander populations: an analysis of a negative life events scale. Int J Equity Health 2007, 6(18):1-12.

19. Garvey D: A review of the social and emotional wellbeing of Indigenous Australian peoples - considerations, challenges and opportunities. Australian Indigenous HealthinfoNet 2008, 8(4):1-29.

20. Dingwall KM, Cairney S: Psychological and cognitive assessment of indigenous Australians. Aust N Z J Psychiatry 2010, 44(1):20-30.

21. Lutschini M: Engaging with holism in Australian Aboriginal health policy - a review. Australia and New Zealand health policy 2005, 2:15.

22. McEwan A, Tsey K, Empowerment Research Team: The role of spirituality in social and emotional wellbeing initiatives: the family wellbeing program at Yarrabah. Darwin: Cooperative Research Centre for Aboriginal Health; 2008

23. Swan P, Raphael B: Ways Forward: National Aboriginal and Torres Strait Islander Mental Health Policy National Consultancy Report. Canberra: Australian Government Publishing Service; 1995:1-272.

24. Jorm AF, Bourchier SJ, Cvetkovski S, Stewart G: Mental health of Indigenous Australians: a review of findings from community surveys. Med J Aust 2012, 196(2):118-121.

25. Zubrick SR, Silburn SR, Lawrence DM, Mitrou FG, Dalby RB, Blair EM, Griffin J, Milroy H, De Maio JA, Cox A, et al: The Western Australian aboriginal child health survey: the social and emotional wellbeing of aboriginal children and young people. Perth: Curtin University of Technology and Telethon Institute for Child Health Research; 2005:1-630.

26. Thomas A, Cairney S, Gunthorpe W, Paradies Y, Sayers S: Strong Souls: development and validation of a culturally appropriate tool for assessment of social and emotional well-being in Indigenous youth. Aust N Z J Psychiatry 2010, 44(1):40-48.

27. Zubrick SR, Lawrence DM, de Maio J, Biddle N: Testing the reliability of a measure of aboriginal children's mental health: an analysis based on the Western Australian aboriginal child health survey. In Cat no 1351055011. Canberra: Commonwealth of Australia, Australian Bureau of Statistics; 2006.

28. Skelton F, Kikkawa D: Social and emotional wellbeing and learning to read English. In Footprints in time: The Longitudinal Study of Indigenous Children, Report from Wave 4.. Canberra: Department of Families, Housing, Community Services and Indigenous Affairs; 2013.

29. Goodman R: Psychometric properties of the strengths and difficulties questionnaire. J Am Acad Child Adolesc Psychiatry 2001, 40(11):1337-1345.

30. Australian Bureau of Statistics: National Aboriginal and Torres Strait Islander Social Survey: Technical Manual, 2002. In Cat no 471755001. Canberra: Commonwealth of Australia; 2004

31. Australian Bureau of Statistics: ABS Directions in Aboriginal and Torres Strait Islander Statistics, Jun 2007. In Cat no 47000. Canberra: Commonwealth of Australia; 2007. 
32. Stevens $M$, Young M: Betting on the evidence: reported gambling problems amongst the indigenous population of the northern territory. Australia and New Zealand Journal of Public Health 2009, 33(6):556-565.

33. Stevens M, Young M: Independent correlates of reported gambling problems amongst Indigenous Australians. Soc Indic Res 2010, 98(1):147-166.

34. Australian Bureau of Statistics: National Aboriginal and Torres Strait Islander Social Survey: Users Guide, 2008. In Cat no 47200. Canberra: Commonwealth of Australia; 2010.

35. Australian Bureau of Statistics: Australian Standard Geographical Classification (ASGC). In Cat no 12160. Canberra: Commonwealth of Australia; 2008.

36. Australian Bureau of Statistics: Housing and Infrastructure in Aboriginal and Torres Strait Communities, Australia, 2001. In Cat no 47100. Canberra: Commonwealth of Australia; 2002.

37. Everitt BS, Dunn G: Applied Multivariate Data Analysis. London: Arnold; 2001.

38. Bryant FB, Yarnold PR: Principal-components analysis and exploratory and confirmatory factor analysis. In Reading and Understanding Multivariate Statistics. Edited by Grimm LG, Yarnold PR. Washington DC: American Psychological Association; 1995.

39. Australian Bureau of Statistics: Remote Access Data Laboratory (RADL) User Guide. In Cat no 1406055002. Canberra: Commonwealth of Australia; 2012.

40. Australian Bureau of Statistics: General social survey, 2006: users guide. In Cat no 415955002. Canberra: Commonwealth of Australia; 2007.

41. Australian Bureau of Statistics: National Aboriginal and Torres Strait Islander Social Survey, Australia, 2002. In Cat no 4717055001. Canberra: Commonwealth of Australia; 2004.

42. Australian Bureau of Statistics: General social survey: summary results, Australia, 2002. In Cat no 4159055006. Canberra: Commonwealth of Australia; 2004.

43. Australian Bureau of Statistics: General social survey: summary results, Australia, 2006. In Cat no 41590. Canberra: Commonwealth of Australia; 2007.

44. Stevens M, Young M: Reported gambling problems in the indigenous and total Australian population. Melbourne: Office of Gaming and Racing Department of Justice for Gambling Research Australia; 2009:1-75.

45. Bailie R, Stevens M, McDonald E, Halpin S, Brewster D, Robinson G, Guthridge S: Skin infection, housing and social circumstances in children living in remote Indigenous communities: testing conceptual and methodological approaches. BMC Public Health 2005, 5(1):128.

46. Wild R, Anderson P: Ampe Akelyernemane Meke Mekarle "Little Children are Sacred": Report of the Northern Territory Board of Inquiry into the Protection of Aboriginal Children from Sexual Abuse. Darwin: Northern Territory Government; 2007.

47. Hunter EM: Aboriginal Health and History, Power and Prejudice in Remote Australia. Cambridge: Cambridge University Press; 1993.

48. McKnight D: From hunting to drinking: The devastating effects of alcohol on an Australian Aboriginal community. London: Routledge; 2002.

49. Martin DF: Autonomy and relatedness: An ethnography of Wik people of Aurukun, western Cape York Peninsula. PhD. Canberra: Australia National University; 1993.

50. Australian Bureau of Statistics, Australian Institute of Health \& Welfare: The Health and Welfare of Australia's Aboriginal and Torres Strait Islander Peoples, 2010. In Cat no 47040. Canberra: Commonwealth of Australia; 2010.

51. Hunter B, Biddle N: Survey Analysis for Indigenous Policy in Australia: Social Science Perspectives. Canberra: Australia National University; 2012.

52. Aboriginal Health \& Medical Research Council of NSW: Pressing problems: Gambling issues and responses for NSW Aboriginal communities. Sydney: NSW Government; 2007.

53. Brady M, Nicholls R, Henderson G, Byrne JOE: The role of a rural sobering-up centre in managing alcohol-related harm to Aboriginal people in South Australia. Drug And Alcohol Review 2006, 25(3):201-206.

54. Calabria B, Clifford A, Shakeshaft A, Allan J, Bliss D, Doran C: The acceptability to Aboriginal Australians of a family-based intervention to reduce alcoholrelated harms. Drug And Alcohol Review 2013, 32(3):328-332.

55. Cultural Perspectives Pty Ltd: Research into health promotion and best practice services for Indigenous diverse communities. In Edited by Justice VGD. Melbourne, Victoria, Australia: Office for Gaming and Racing; 2005.

56. Hing N, Breen H, Gordon A, Russell A: Risk factors for problem gambling among indigenous Australians: an empirical study. J Gamb/ Stud 2013:1-16. doi: 10.1007/s10899-013-9364-y. Online ISSN 1573-3602.

57. Chikritzhs T, Brady M: Fact or fiction? a critique of the national aboriginal and torres strait islander social survey 2002. Drug And Alcohol Review 2006, 25(3):277-287.
58. Chikritzhs T, Liang W: Does the 2008 NATSISS underestimate the prevalence of high risk Indigenous drinking? In Survey analysis for indigenous policy in Australia : social science perspectives. Volume Research Monograph No. 32, edn. Edited by Hunter B, Biddle N. The Australian National University, Canberra: Centre for Aboriginal Economic Policy Research College of Arts and Social Sciences; 2012:49-64.

59. Northern Territory Government: Closing the gap on indigenous disadvantage: a generational plan of action. Darwin: Northern Territory Government; 2007

60. Northern Territory Government: Growing them Strong, Together: Promoting the safety and wellbeing of the Northern Territory's children, Summary Report of the Board of Inquiry into the Child Protection System in the NT Northern Territory 2010. Darwin: Northern Territory Government; 2010.

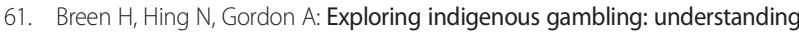
indigenous gambling behaviour, consequences, risk factors and potential interventions. Lismore: Southern Cross University; 2010:1-242.

62. Hunter EM, Spargo RM: What's the big deal? Aboriginal gambling in the Kimberley region. Med J Aust 1988, 149(11-12):668-672.

63. Paradies $Y$ : A review of psychosocial stress and chronic disease for 4 th world indigenous peoples and African Americans. Ethn Dis 2006, 16(1):295-308.

doi:10.1186/1471-2458-14-144

Cite this article as: Stevens and Paradies: Changes in exposure to 'life stressors' in the Aboriginal and Torres Strait Islander population, 2002 to 2008. BMC Public Health 2014 14:144.

\section{Submit your next manuscript to BioMed Central and take full advantage of:}

- Convenient online submission

- Thorough peer review

- No space constraints or color figure charges

- Immediate publication on acceptance

- Inclusion in PubMed, CAS, Scopus and Google Scholar

- Research which is freely available for redistribution

Submit your manuscript at www.biomedcentral.com/submit
C) Biomed Central 